\title{
A Strategy for Synthesis of Azide Polymers via Controlled/Living Free Radical Copolymerization of Allyl Azide under ${ }^{60} \mathrm{Co}$ Y-Ray Irradiation
}

Daoben Hua, Wei Bai, Junpeng Xiao, Ruke Bai*, Weiqi Lu, Caiyuan Pan

Department of Polymer Science and Engineering, University of Science and Technology of China, Hefei, P. R. China, 230026

*E-mail: bairk@ustc.edu.cn

Synthesis of Allyl azide: A typical synthesis procedure of allyl azide is as follows. Caution! The experiment should be accompanied with a protective shield. To a mixture of sodium azide $(0.05 \mathrm{~mol})$, Tetrabutylammonium bromide $(0.02 \mathrm{~g})$, and $\mathrm{H}_{2} \mathrm{O}(15 \mathrm{~mL})$, 3-bromoprop-1-ene $(0.05 \mathrm{~mol})$ is added dropwise at $0{ }^{\circ} \mathrm{C}$. After that, the reaction mixture was stirred for $1.5 \mathrm{hrs}$, and then poured into crushed ice and extracted with diethyl ether $(2 \times 5 \mathrm{~mL})$, the combined organic extracts were washed with cold water $(2 \times 15 \mathrm{~mL})$, dried (anhydrous $\left.\mathrm{MgSO}_{4}\right)$, evaporated under reduced pressure at low temperature $\left(<10{ }^{\circ} \mathrm{C}\right)$ to afford product $(3.57 \mathrm{~g}, 86.1 \%$ yield $) .{ }^{1} \mathrm{H}$ NMR $(300 \mathrm{MHz}$, $\left.\mathrm{CDCl}_{3}, \delta\right): 5.81-5.92(\mathrm{~m}, 1 \mathrm{H},-\mathrm{CH}=), 5.28-5.36\left(\mathrm{~m}, 2 \mathrm{H}, \mathrm{CH}_{2}=\right), 3.77\left(\mathrm{~d}, 2 \mathrm{H},-\mathrm{CH}_{2}-\right) . \mathrm{IR}$ $(\mathrm{KBr}, \mathrm{v}): 2102.7 \mathrm{~cm}^{-1}\left(-\mathrm{N}_{3}\right)$.

Polymerization: The polymerizations were performed in a sealed tube under ${ }^{60} \mathrm{Co} Y$ -ray irradiation $\left(60 \mathrm{Gymin}^{-1}\right)$ at $0^{\circ} \mathrm{C}$. The mixture of monomers ([Comonomer]/[AAz] $=3 \mathrm{~mol} / \mathrm{mol})$ and BPDTC $\left([\right.$ BPDTC $\left.]=0.0188 \mathrm{~mol} \mathrm{~L}^{-1}\right)$ was placed in a $5 \mathrm{~mL}$ 
polymerization tube. After it was degassed with performing a freeze-evacuate-thaw cycle three times, the tube was sealed under vacuum. Then it was placed in an insulated room with a ${ }^{60} \mathrm{Co}$ source. After the polymerization, the reaction mixture was dissolved with THF, and then precipitated in 10-fold n-hexane. The polymer was collected by filtration and dried under reduced pressure at room temperature $\left(\sim 25^{\circ} \mathrm{C}\right)$.
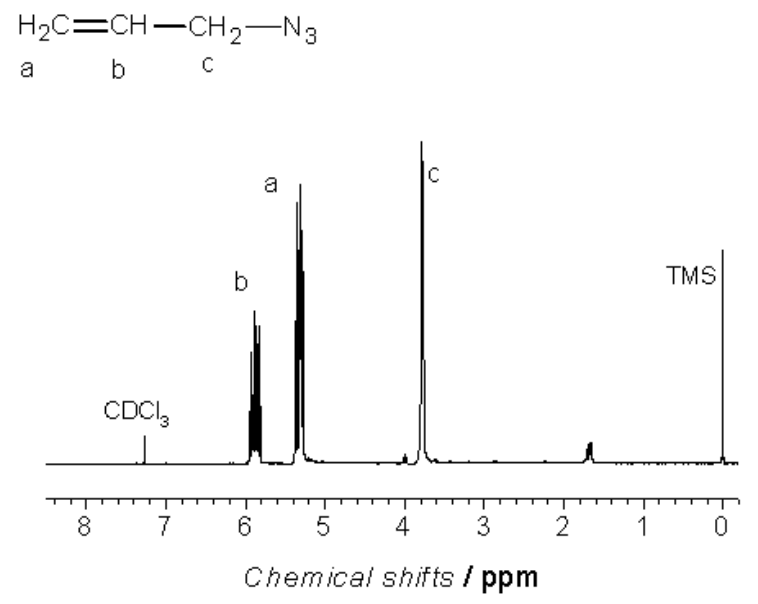

Fig. $1{ }^{1} \mathrm{H}$ NMR of allyl azide.

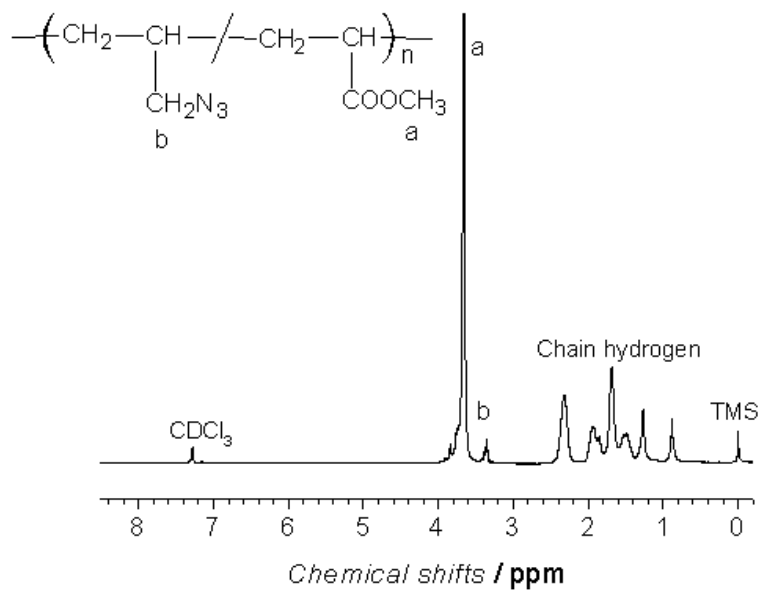

Fig. $2{ }^{1} \mathrm{H}$ NMR of poly(AAz-co-MA) $\left(\mathrm{M}_{\mathrm{n}}=10500, \mathrm{M}_{\mathrm{w}} / \mathrm{M}_{\mathrm{n}}=1.10\right)$. 


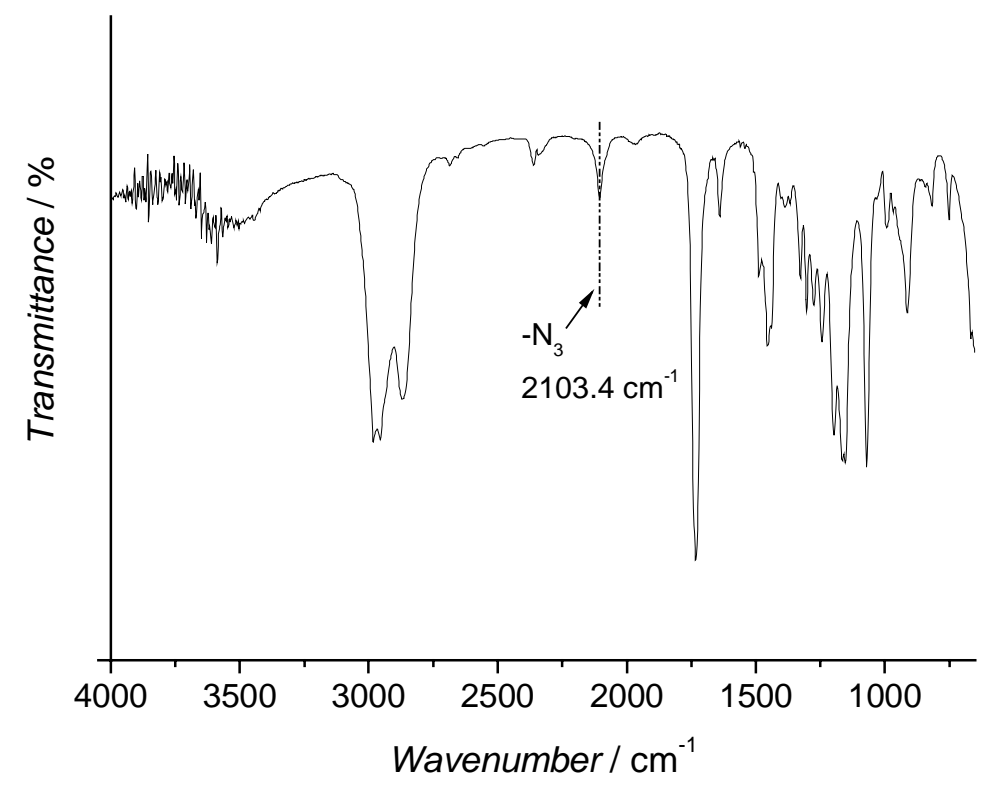

Fig. 3 FTIR spectrum of poly(AAz-co-MMA) $\left(M_{n}=16200, M_{w} / M_{n}=1.16\right)$ on $\mathrm{KBr}$ tablet.

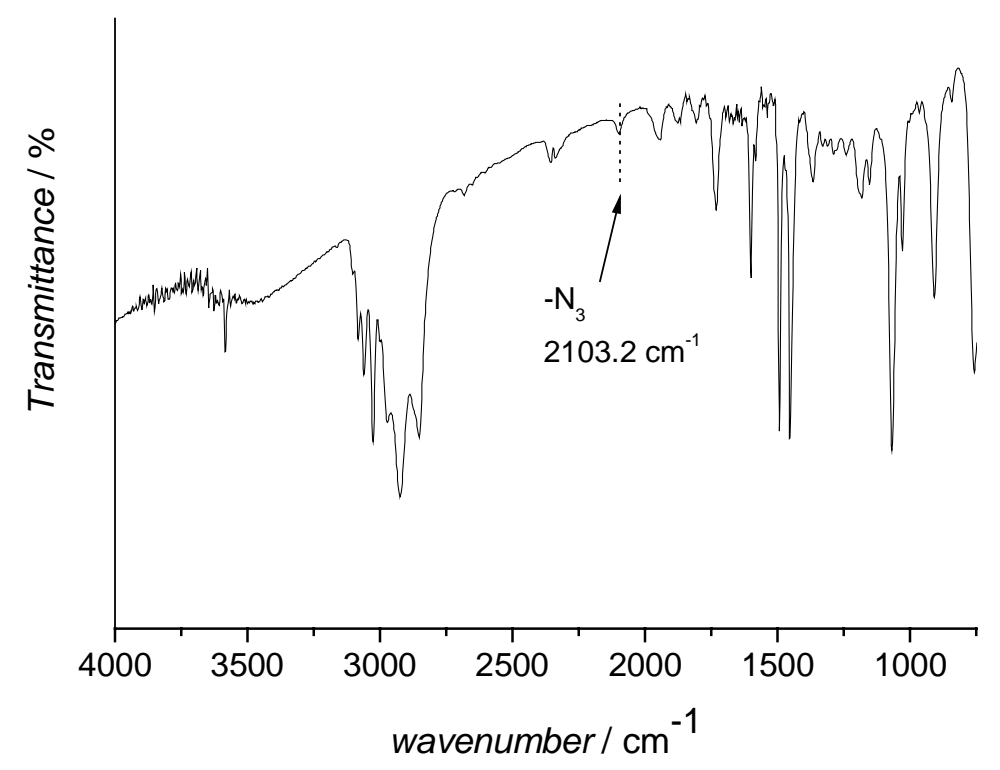

Fig. 4 FTIR spectrum of poly $(A A z-c o-S t)\left(M_{n}=9600, M_{w} / M_{n}=1.29\right)$ on $\mathrm{KBr}$ tablet. 